\title{
Characteristics UWB Planar Antenna With Dual Notched Bands For WIMAX And WLAN
}

\author{
Debab Mohamed ${ }^{1}$, Mahdjoub Zoubir ${ }^{1}$ \\ ${ }^{1}$ Electromagnetic Photonics Optronics Laboratory (EPOL), University of Sidi Bel Abbès, 22000 Sidi Bel Abbès, Algeria \\ *corresponding author, E-mail: debab_telecoms2005@hotmail.fr
}

\begin{abstract}
In this article, a novel design of ultra-wideband (UWB) monopole antenna with dual notched band performance is proposed. The size of the UWB antenna is minimized to $20 \times 17.6 \mathrm{~mm}^{2}$, printed on a FR4 substrate with $1.5 \mathrm{~mm}$ thickness and loss tangent of $\tan \delta=0.02$, and is fed by a coplanar waveguide (CPW). The operation bandwidth of the designed antenna is from $3.1 \mathrm{GHz}$ to more than $10 \mathrm{GHz}$. Band notch characteristics of the antenna to reject the frequency band, WIMAX band (3.1-3.9GHz) and WLAN band $(5.1-5.9 \mathrm{GHz})$, is realized by cutting three quarter wavelength slots in the radiating patch. A quarter wavelength slot in the radiator of the antenna is used to create a frequency band notch at the WIMAX frequency band. However, the WLAN frequency band is notched using two symmetrical quarter wavelength slots. The proposed antenna is simulated using HFSS and CST high frequency simulators. These results are compared with measured results by using a network analyzer.
\end{abstract}

\section{Introduction}

Due to the progress in wireless communication systems and the increase in their applications, ultra-wideband (UWB) technology has recently become one of the most fascinating advancements for high transmission rate indoor and outdoor wireless communications, and for low power consumption. The work in this area has gained prominence with the Federal Communications Commission (FCC) [1] allowing for the marketing and exploitation of UWB products within the band 3.1-10.6 GHz. This technology has offered unique advantages not achievable by conventional narrowband technology and simple hardware configuration [2-4], many emerging microwave technologies and applications are operating on UWB band. However, since the designated UWB frequency band overlaps the existing WIMAX and WLAN operating band (3.3-3.8 GHz) $(5.15-5.825 \mathrm{GHz})$, UWB antenna with the band notched characteristic is a main requirement to avoid interference with the existing narrow systems. The interference levels can be suppressed by using band stop filters, but this will increase the cost and require more space, however, most of the antennas in the current literature have a large size. There are many methods with which we can achieve a band notch characteristic in UWB antenna [5-14]. Another method to generate the band notched function is to put in parasitic elements [15], and a split ring resonator (SRR) type slot has been embedded on the patch to obtain notch characteristic at WLAN and WIMAX [16]. In [17], an electromagnetic band gap (EBG) structure is used to create notched bands. The main challenge for the design of multiband notched antenna is to minimize fabrication costs and the mutual coupling of slots, because of the small area available for them within the antenna. A sufficient rejection bandwidth and the ability to control bandwidth of the notched band is needed.

In this article, we propose a simple method to realize the dual band notched characteristics for a compact UWB monopole antenna, using only triple straight slots etched in the radiator patch.

The effect geometry antenna and design principle with variable frequency band notch characteristic are explained in Section 2. The radiation pattern, simulation, and measurement results of return loss are presented in Section 3. The concluding remarks are given in Section 4.

\section{Antenna Design}

The design procedure begins by finding dimension of the antenna feeder to give $50 \Omega$ characteristic impedance $Z_{C}$, is calculated by formula (1) [18]:

$$
\begin{gathered}
\mathrm{Z}_{\mathrm{C}}=\frac{30 \pi}{\sqrt{\varepsilon_{\mathrm{e}}}} \frac{\mathrm{K}^{\prime}(\mathrm{k})}{\mathrm{K}(\mathrm{k})} \\
\mathrm{k}=\frac{\mathrm{W}_{1}}{\mathrm{w}_{1}+2 \mathrm{~g}} \\
\varepsilon_{\text {eff }}=\frac{\varepsilon_{\mathrm{r}}+1}{2}[\mathrm{~A}+\mathrm{B}] \\
\mathrm{A}=\tanh \left\{1.785 \log \left(\frac{\mathrm{h}}{\mathrm{g}}\right)+1.75\right\} \\
\mathrm{B}=\frac{\mathrm{kg}}{\mathrm{h}}\left\{0.04-0.7 \mathrm{k}+0.01\left(1-0.1 \varepsilon_{\mathrm{r}}\right)(0.25+\mathrm{k})\right\}
\end{gathered}
$$


Where $K(k)$ is the first kind elliptical integral and $K^{\prime}(k)=$ $\mathrm{K}\left(\sqrt{1-\mathrm{k}^{2}}\right), \mathrm{W}_{1}$ is the central strip width, whereas $\mathrm{g}$ is the gap width between the CPW fed wire and the ground, $\varepsilon_{\mathrm{r}}$ is the relative dielectric constant of the substrate, and $h$ is the substrate thickness. The proposed antenna with dual band notched UWB antenna are shown in Figure 1. The antenna is a trapezoidal radiating element with three slots $\mathrm{S}_{1}, \mathrm{~S}_{2}$, and $\mathrm{S}_{3}$. In the design, a substrate with a relative dielectric constant of 4.4 and thickness of $1.5 \mathrm{~mm}$ is employed. The 50 $\Omega \mathrm{CPW}$ feed structure consists of a transmission line with a width of $\mathrm{W}_{1}=3 \mathrm{~mm}$, and $\mathrm{g}=0.5 \mathrm{~mm}$ is the gap between the transmission line and the ground plane. A commercial computer simulation tool High Frequency Structure Simulator (HFSS), is used to design the antenna. The optimized dimensions are presented in Table 1.

Table 1: Dimensions of proposed antenna (mm).

\begin{tabular}{|c|c|c|c|}
\hline parameter & (mm) & parameter & $(\mathbf{m m})$ \\
\hline $\mathbf{W}$ & 17.6 & Ls1 & 12.8 \\
\hline $\mathbf{L}$ & 20 & $\mathbf{L}_{\mathbf{2} 2}, \mathbf{L}_{\mathbf{S 3}}$ & 7.8 \\
\hline $\mathbf{W}_{1}$ & 3 & g & 0.5 \\
\hline $\mathbf{L}_{1}$ & 6.4 & $\mathbf{t}_{\text {slot }}$ & 0.3 \\
\hline $\mathbf{L}_{2}$ & 1.3 & $\mathbf{y}$ & 2.5 \\
\hline $\mathbf{L g}_{\mathrm{g}}$ & 4.6 & $\mathbf{y}_{1}$ & 7 \\
\hline
\end{tabular}

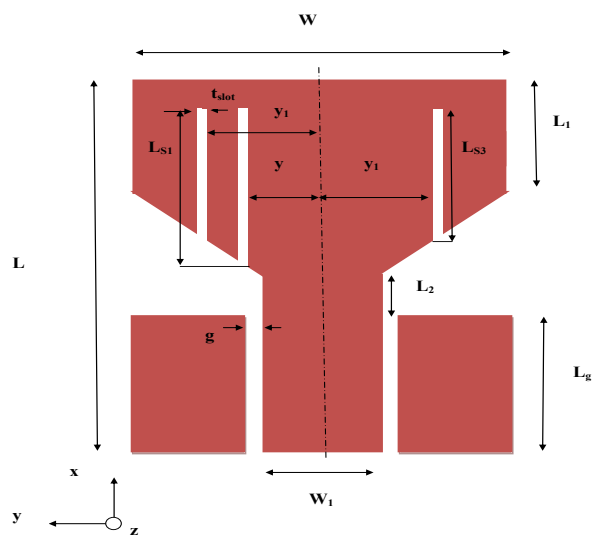

(a)

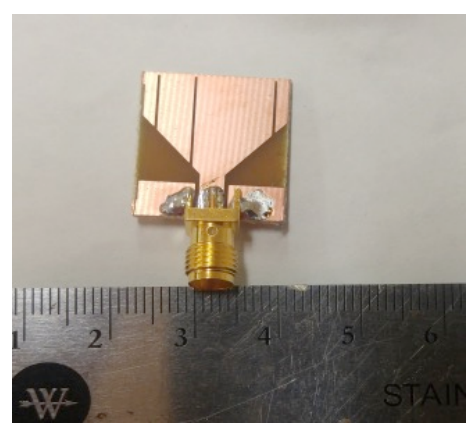

(b)

Figure 1: (a) Geometry of the antenna. (b) Photograph of the fabricated antenna.

\section{A. Basic Antenna Design}

In this section, the effects of changing the geometric parameters of the proposed antenna without slots on impedance matching and bandwidth are discussed.

The ground plane affects the characteristics of the antenna. Figure 2 shows the simulated VSWR when $\mathrm{Lg}_{\mathrm{g}}$ is altered from 3.8 to $5 \mathrm{~mm}$. It can be seen that the impedance bandwidth of the antenna decreases as $\mathrm{Lg}$ increases from 3.9 to $5 \mathrm{~mm}$, as the lower edge of the bandwidth increases. The input impedance of the radiating patch becomes mismatched when $\mathrm{Lg}$ decreases to $3.8 \mathrm{~mm}$, therefore, we decided on $\mathrm{Lg}=4.6 \mathrm{~mm}$ as the optimum with the bandwidth from 3.1 to more than $10 \mathrm{GHz}$.

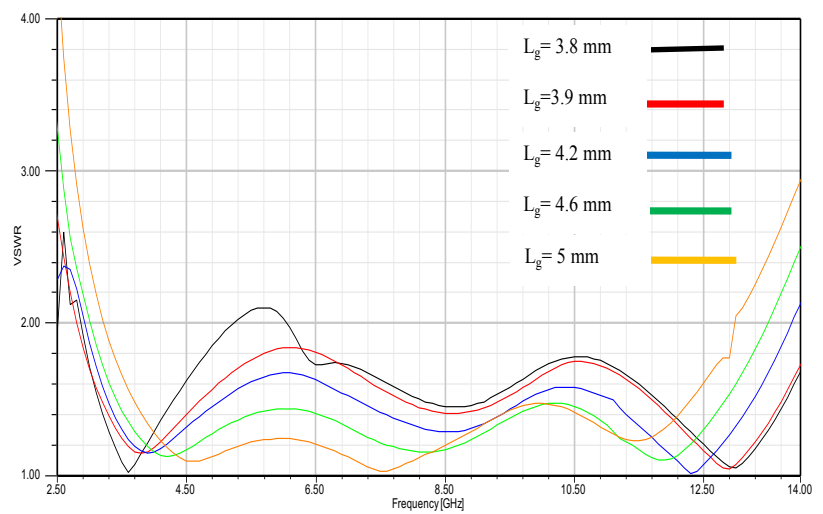

Figure 2: VSWR of the basic antenna without the slots for different values of $\mathrm{Lg}$.

With $\mathrm{Lg}$ is fixed at $4.6 \mathrm{~mm}$, the simulated VSWR with different values $\mathrm{L}_{1}$ are shown in Figure 3. It is clear when $\mathrm{L}_{1}$ increases from 5.65 to $7.4 \mathrm{~mm}$ the higher edge of the bandwidth increases, and when $\mathrm{L}_{1}=8.65 \mathrm{~mm}$, the antenna performance becomes worse. To achieve the maximum impedance bandwidth we have selected an optimal value of $\mathrm{L}_{1}=6.4 \mathrm{~mm}$.

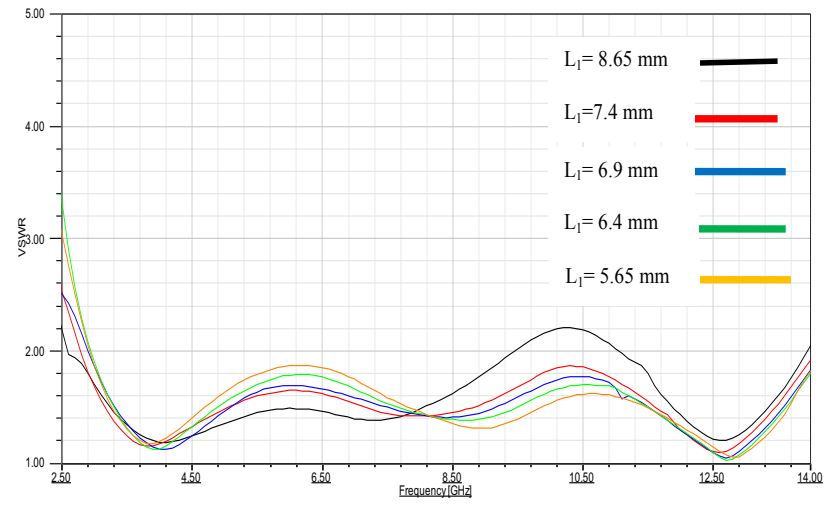

Figure 3: VSWR of the basic antenna without the slots for different values of $L_{1}$. 


\section{B. Configuration of UWB Antenna with variable frequency Band Notch characteristic}

UWB antenna without slots is illustrated in Figure 4(a) and is denoted as antenna-1. To implement the band notched characteristic, two UWB antennas with single notch bands are designed by using the simple or double quarter wavelength slots, shown in Figures 4(b) and 4(c), respectively. The location and shapes of the slots were determined as shown in Figure 4. In designing the slots, we used guided wavelength $\lambda_{g}=\frac{\lambda_{0}}{\sqrt{\varepsilon_{\mathrm{eff}}}}$, where $\lambda_{0}$ is the free space wavelength and the length slot is defined by:

$$
L_{S}=\frac{\lambda \mathrm{g}}{4}
$$

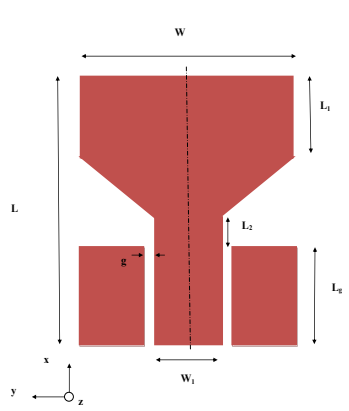

(a) Antenna 1

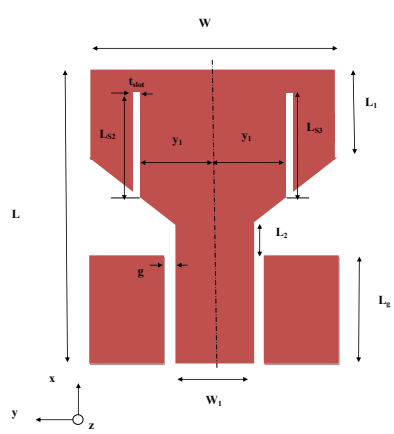

(c) Antenna 3

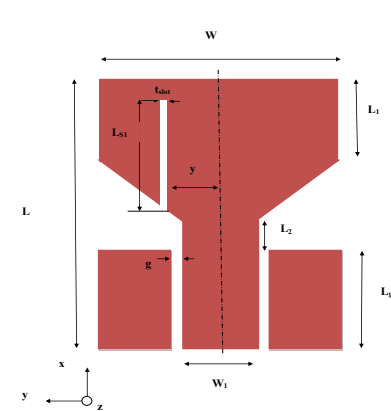

(b) Antenna 2

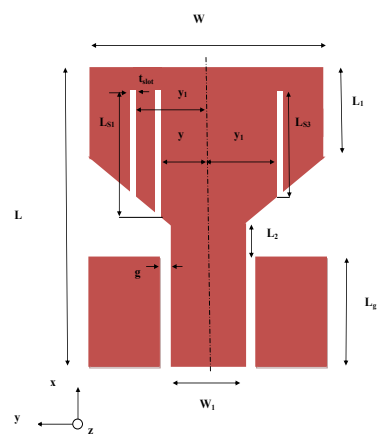

(d) Antenna 4
Figure 4: Steps of improvement of the proposed antenna.

Three slots with the same line width tslot were embedded in the radiating patch. In Figure 4(b), the length of slot $\mathrm{S}_{1}$, $\mathrm{Ls}_{1}=12.8 \mathrm{~mm}$, is approximated as a quarter of the guided wavelength, corresponding to the resonant frequency of the WIMAX band, $3.5 \mathrm{GHz}$, and distance $\mathrm{y}=2.5 \mathrm{~mm}$ from the center line of the patch radiator. Figure 4(c) shows the other single band notched UWB antenna with the double slots $\mathrm{S}_{2}$ and $\mathrm{S}_{3}$, the length $\mathrm{L}_{\mathrm{S} 2}=\mathrm{L}_{\mathrm{S} 3}=7.8 \mathrm{~mm}$, is approximated as a quarter of the guided wavelength corresponding to the resonant frequency of the WLAN band $5.5 \mathrm{GHz}$, slots are arranged to be symmetric to the centerline of the patch radiator with distance $\mathrm{y}_{1}=7 \mathrm{~mm}$. Finally, the addition of the slot and double slots with $\mathrm{y}$ and $\mathrm{y}_{1}$ distances respectively, are employed to realize the desired two stop bands, and the resulting dual band notched UWB antenna is illustrated in Figure 4(d).

Figure 5 shows the VSWR curves of the proposed UWB antenna with (antenne-2) notch at WIMAX band (3.1$4 \mathrm{GHz}$ ), (antenna-3) notch at WLAN band(5.18-5.9GHz), and (antenna -4) notches at both WIMAX $(3.1-3.9 \mathrm{GHz})$ and WLAN band $(5.1-5.9 \mathrm{GHz})$. It is clear from Figure 5 that with the introduction of straight slot $\mathrm{S}_{1}$ with distance $\mathrm{y}=2.5 \mathrm{~mm}$ the center line of the planar element, narrow rejection band with VSWR $>2$ is obtained for WIMAX frequencies. When the double slots $\mathrm{S}_{2}$ and $\mathrm{S}_{3}$ are arranged to be symmetric to the center line of the planar element with distance $\mathrm{y}_{1}=7 \mathrm{~mm}$, WLAN band is rejected.

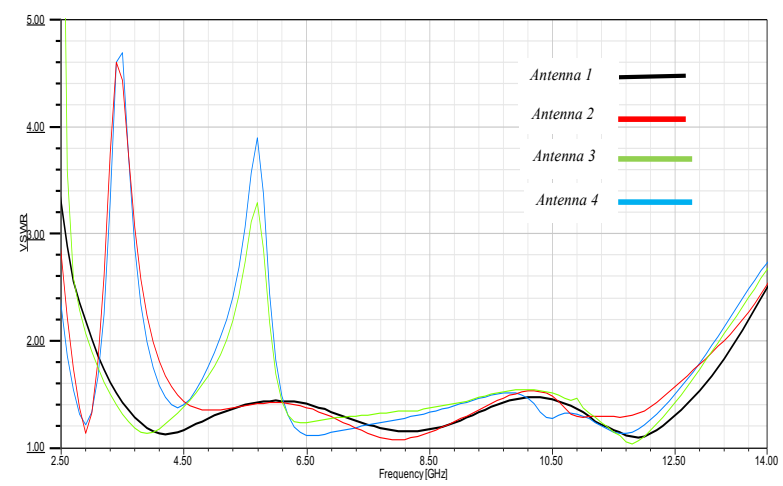

Figure 5: VSWR of the proposed antenna with and without slots.

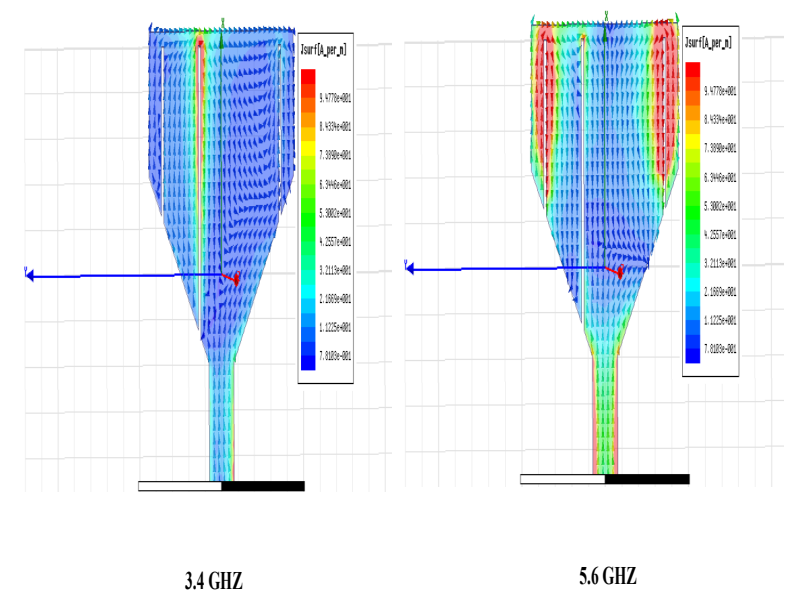

Figure 6: Simulated current density distribution of the antenna at 3.5 and $5.6 \mathrm{GHz}$.

Figure 6 shows the simulated current distributions under the proposed antenna at the notched frequencies. It can be seen that the current is concentrated on the inner and outer edges of straight slots. The current paths around the straight slots 
are in opposite directions that results in a notch performance at this frequency.

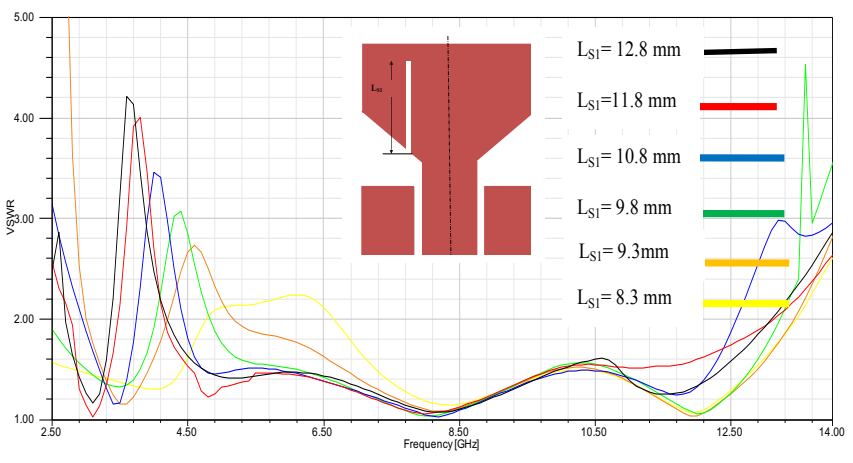

(a)

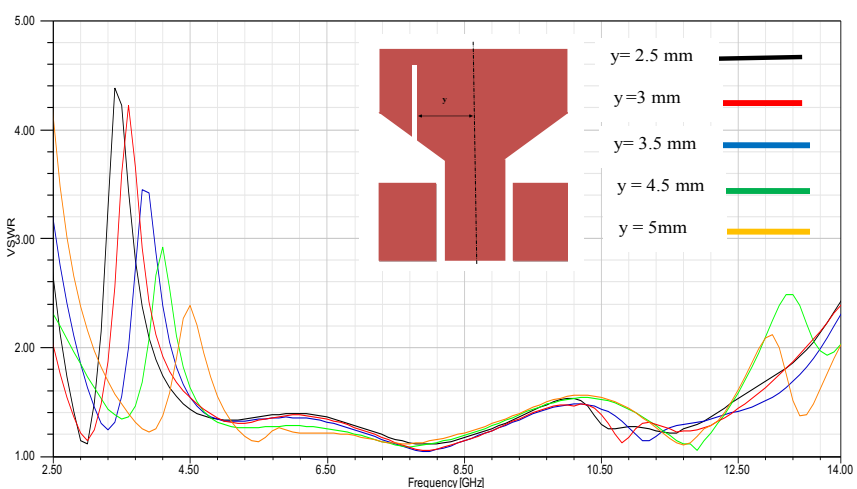

(b)

Figure 7: Simulated VSWR characteristic for various values of $\mathrm{L}_{\mathrm{S} 1}$ (a) and y (b) for antenna-2 (Figure 4).

The notched bands can be affected by the length and location of the slots. From Figure 7(a) and (b), it can be seen that when the length of the slot gets shorter, its rejection frequency goes higher but with lower amplitude of the notched band. The center frequency of the notched band increases from 3.5 to $4.5 \mathrm{GHz}$ as y increases from 2.5 to $5 \mathrm{~mm}$. For $\mathrm{y}=2.5 \mathrm{~mm}$, when Ls1 varies from $12.8 \mathrm{~mm}$ to $9.3 \mathrm{~mm}$, the center notch frequency varies from 3.5 to $4.5 \mathrm{GHz}$, and the amplitude of the notched band is much reduced when $\mathrm{Ls}_{1}=8.3 \mathrm{~mm}$. Thus, the single quart wavelength slot can only create a band notch at a lower frequency of $5 \mathrm{GHz}$. Therefore, the combinative effect with identical slots Ls2 and Ls3 shows a large improvement in the characteristics of the notched band for WLAN compared to the antenna with a single slot Ls2 as observed in Figure 8.

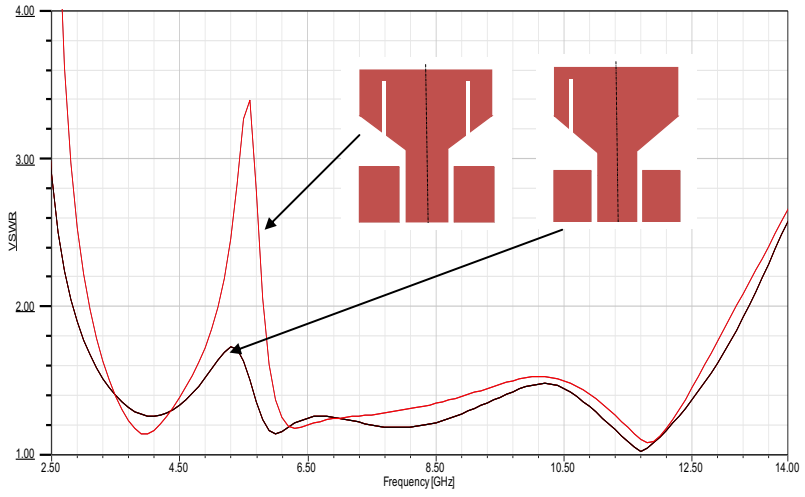

Figure 8: Comparison between the antenna having double slots $\mathrm{L}_{\mathbf{S} 2}$ and $\mathrm{L}_{\mathrm{S} 3}$ and the antenna having only a single slot $\mathrm{L}_{\mathrm{S} 2}$.

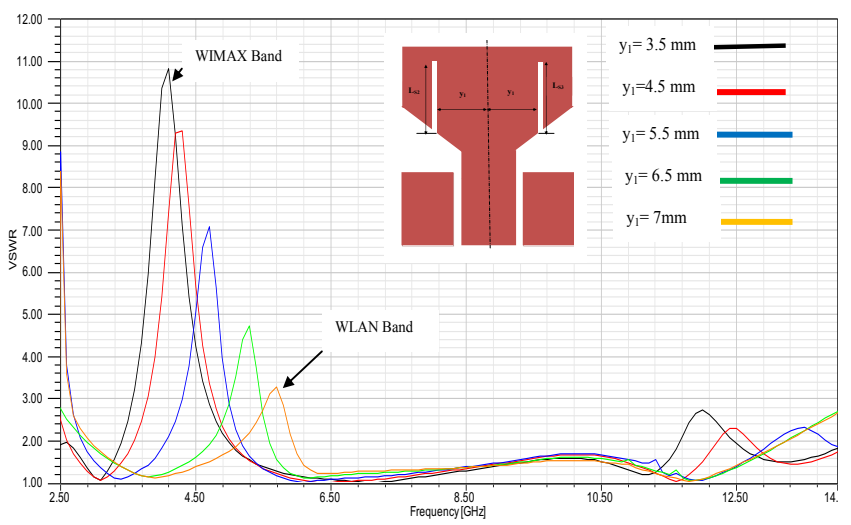

Figure 9: Effect of varying the location of the slots $L_{S 2}$ and Ls3.

Figure 9 shows the effects of location of slots with antenna-3 (Figure 4). The center frequency of the notched band decreases from 5.7 to $3.9 \mathrm{GHz}$ as $\mathrm{y}_{1}$ decreases from 7 to $3.5 \mathrm{~mm}$, because the length of slots $L_{\mathrm{s} 2}$ and $L_{\mathrm{S} 3}$ varied due to the slope-shaped edge of the radiating patch. From these results, it can be said that the antenna- 3 could be a good candidate for the UWB with a single notched band. The notch frequency can be controlled with the WIMAX band to WLAN band, by changing the location of slots from the center line of antenna. 


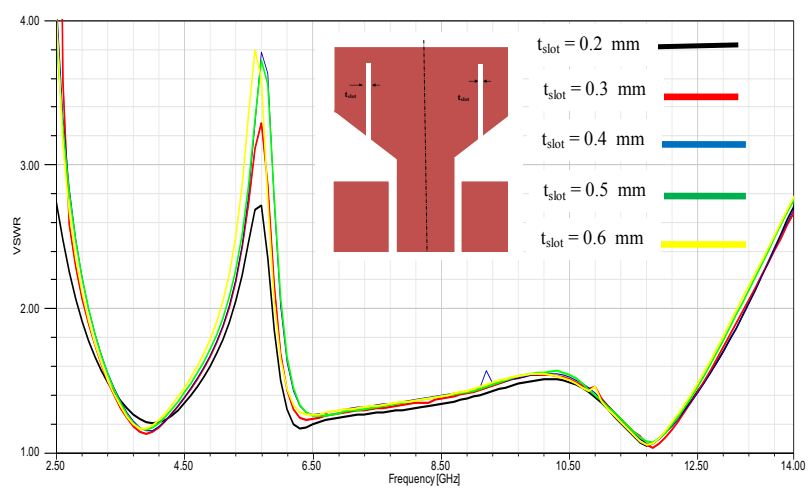

Figure 10: Effect of varying the width of the slots $t_{\text {slot. }}$

Figure 10 illustrates the effect the width tslot of the slots, it causes a wider notch bandwidth, from 0.2 to $0.6 \mathrm{~mm}$, and the filter bandwidth is varied from 0.6 to $0.9 \mathrm{GHz}$.

\section{Results}

The proposed antenna has been constructed and tested by using CST MWS and HFSS software, and measured by using a vector network analyzer. Figure 11 shows the simulated and measured VSWR. The measurement result show similarity between simulated results, and presents an impedance bandwidth with good matching for VSWR $\leq 2$ from $3.1 \mathrm{GHz}$ to more than $10 \mathrm{GHz}$, with dual rejected bands (VSWR > 2) 3.1-3.9 GHz, and 5.1-5.9GHz. A slight deviation in results is caused by the fabrication tolerance and the effect of the SMA connector.

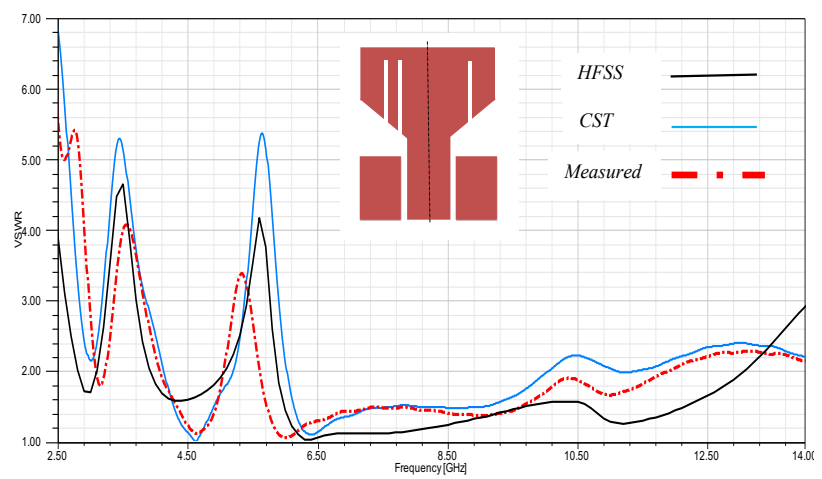

Figure 11: Measured VSWR with simulation results.
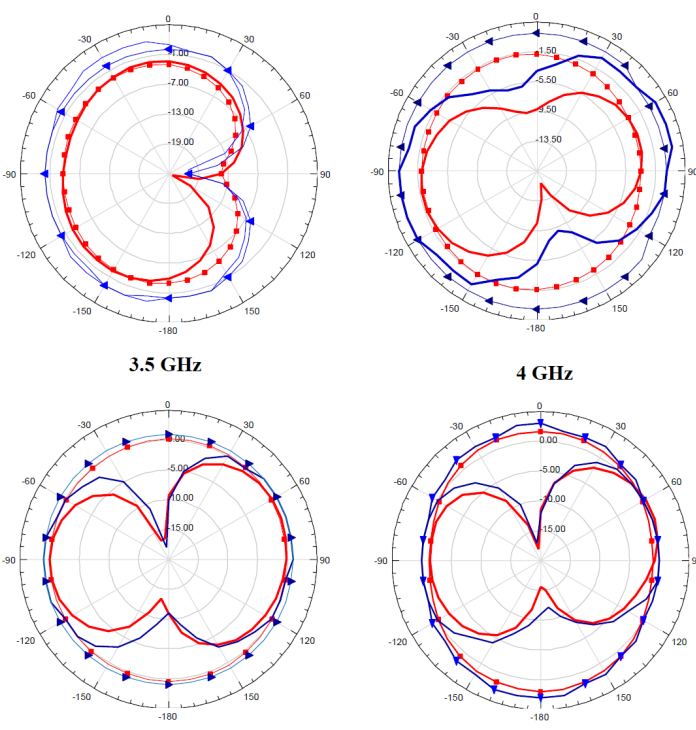

$5.4 \mathrm{GH} z$

$7 \mathrm{GHz}$
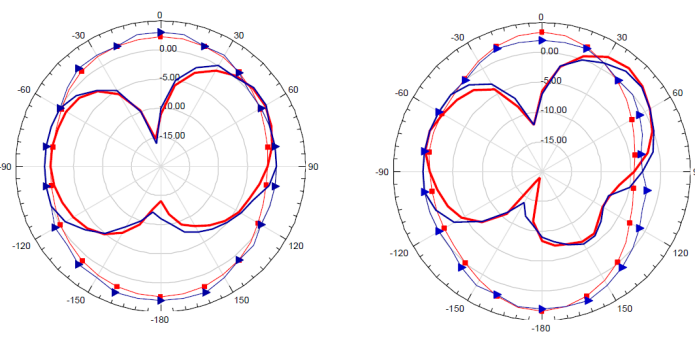

$8 \mathrm{GHz}$

$10 \mathrm{GHz}$

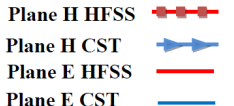

Figure 12: CST and HFSS Simulated directivity patterns in the $\mathrm{H}$ plane $(\mathrm{y}-\mathrm{z})$ and $\mathrm{E}$ plane $(\mathrm{x}-\mathrm{y})$ for the proposed antenna.

Figure 12, shows the simulated radiation patterns, in the $\mathrm{H}-$ plane $(\mathrm{y}-\mathrm{z})$ and E-plane $(\mathrm{x}-\mathrm{y})$ for different frequencies such as $3.5,4,5.4,7,8$, and $10 \mathrm{GHz}$ obtained by the two tools for simulation HFSS and CST. We notice good agreement between the simulated results. The far field radiation in the $\mathrm{H}$-plane are nearly omnidirectional and there are monopole type radiation characteristics in the E-plane.

\section{Conclusion}

In this article, a new ultra wideband antenna has been proposed for WLAN and WIMAX applications. This antenna has a compact size of $20 \times 17.6 \mathrm{~mm}^{2}$ and also a satisfactory characteristic $(\mathrm{VSWR}<2)$ requirement for $3.1 \mathrm{GHz}$ to more than $10 \mathrm{GHz}$. With such a design, dual band notched characteristics for the antenna can be generated at WIMAX band $(3.1-3.9 \mathrm{GHz})$ and WLAN band 
(5.1-5.9 GHz) by simply etching three straight slots on the radiator. The parametric study has showed that the position slots can control the rejected frequency. The antenna prototype has been proposed, implemented, and tested. Measured results show a slight deviation with simulated results (CST MWS and HFSS) programs, which are caused by the fabrication tolerance and the effect of the SMA connector. The radiation pattern of the proposed antenna is nearly omnidirectional throughout the UWB frequency, and stable radiation patterns, indicating it can be suitable for UWB system, for various commercial and military wideband applications.

\section{References}

[1] Federal Communications Commission. First Report and Order. Revision of Part 15 of the Commission's Rules Regarding Ultra-Wideband Transmission Systems. 2002. http://www.fcc.gov.

[2] D. Chao, X. Yong, and L. Ping, "CPW-fed planar printed monopole antenna with impedance bandwidth enhanced ," IEEE Antennas and Wireless Propagation Letters, vol. 8, pp. 1394-97, 2009.

[3] M. N. Jahromi, A. Falahati, and M. Edwards, "Bandwidth and impedance matching enhancement of fractal monopole antennas using compact grounded coplanar waveguide," IEEE Transactions on Antennas and Propagation, vol. 59, no. 7, pp. 2480-87, 2011.

[4] B. Ozbakis and A. Kustepeli, "The resonant behavior of the fibonacci fractal tree antennas," Microwave and Optical Technology Letters, vol. 50, no. 4, pp. 104650, 2008.

[5] C. M. Li and L. H. Ye, "Improved dual band-notched uwb slot antenna with controllable notched band widths," Progress In Electromagnetics Research, vol. 115, pp. 477-93, 2011.

[6] S. Avez and R. W. Aldhaheri, "A Very Compact and Low Profile UWB Planar Antenna with WLAN Band Rejection," The Scientific World Journal, Volume 2016, 7 pages, 2016.

[7] L. Wang-Sang, K. Dong-Zo, K. Ki-Jin, and Y. JongWon, "Wideband planar monopole antennas with dual band notched characteristics," IEEE Transactions on Microwave Theory and Techniques, vol. 54, no. 6, pp. 2800-06, 2006.

[8] R. Eshtiaghi, R. Zaker, J. Nouronia, and C. Ghobadi, "UWB semi elliptical printed monopole antenna with sub band rejection filter," International Journal of Electronic and Communications, vol. 64, no. 2, pp. 133-41, 2010.

[9] W. C. Liu and C. F. Hsu, "Dual-band CPW-fed Yshaped monopole antenna for PCS/WLAN application," Electronics Letters, vol. 41, no. 7, pp. 390-91, 2005.

[10] N. D. Trang, D. H. Lee, and H. C. Park, "Compact printed CPW-fed monopole ultra-wideband antenna with triple sub band notched characteristics,"
Electronics Letters, vol. 46, no. 17, pp. 1177-79, 2010.

[11] N. Ojaroudi, M. Ojaroudi and N. Ghadimi, "Dual band notched small monopole antenna with novel Wshaped conductor backed-plane and novel T-shaped slot for UWB applications," IET Microwaves, Antennas and Propagation, vol. 7, no. 1, pp. 8-14, 2013.

[12] B. Li, J. Hong, and B. Wang, "Switched band-notched UWB/dual-band WLAN slot antenna with inverted Sshaped slots," IEEE Antennas and Wireless Propagation Letters, vol. 11, pp. 572-75, 2012.

[13] J. Y. Deng, Y. Z. Yin, Sh. G. Zhou, and Q. Zh. Liu, "Compact ultra-wideband antenna with tri-band notched characteristic," Electronics Letters, vol. 44, no. 21,pp. 1231-1233, 2008.

[14] A. Valizade, C. Ghobadi, J. Nourinia, and M. Ojaroudi, "A novel design of reconfigurable slot antenna with switchable band notch and multiresonance functions for uwb applications," IEEE Antennas and Wireless Propagation Letters, vol. 11, pp. 1166-69, 2012.

[15] A. M. Abbosh and M. E. Bialkowski, "Design of UWB planar band-notched antenna using parasitic elements," IEEE Transactions Antennas Propagation, vol. 57, no. 3, pp .796-799, 2009.

[16] M. Tang, S. Xiao, T. Deng, D. Wang, J. Guan, B. Wang, and G. Ge, "Compact UWB antenna with multiple band-notches for WiMAX and WLAN," IEEE Transactions Antennas Propagation, vol. 59, no. 4, pp. 1372-76, 2011.

[17] T. Li, H. Q. Zhai, G. H. Li, and C. H. Liang, "Design of compact UWB band-notched antenna by means of electromagnetic-band gap structures," Electronics Letters, vol. 48, no. 11, pp. 608-609, 2012.

[18] K. Gupta, R. Garg, I. Bahl, and P. Bhartis, "Microstrip Lines and Slotlines," Artech House, Boston, Mass, USA, 2nd edition, 1996. 